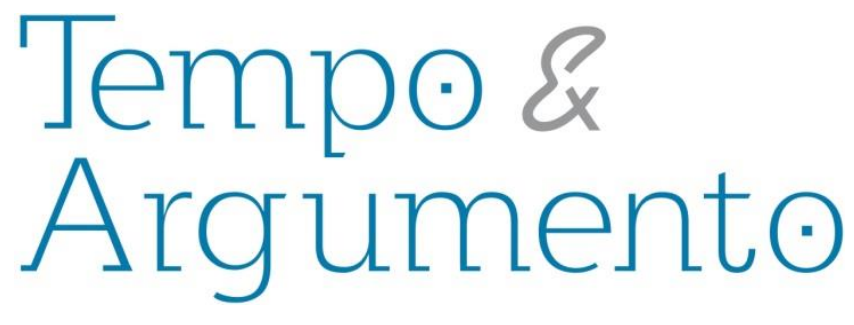

\title{
Primeiros rascunhos: aproximações entre Michel de Certeau e a História do Tempo Presente
}

\begin{abstract}
Resumo
Em um tom propositivo, este texto busca estabelecer aproximações entre as reflexões de Michel de Certeau a respeito da operação historiográfica e a história do tempo presente. A estrutura do texto evidencia o tom marcadamente elucubrador que o direciona: inicialmente, são abordadas as propostas de Michel de Certeau a respeito da operação historiográfica que se concretiza em um fazer e em uma escrita; na sequência, estão as reflexões que buscam nas questões a respeito da epistemologia da distância e do relato histórico os pontos nos quais há possibilidade de enfrentar os dilemas teóricometodológicos da história do tempo presente. Por meio dessas discussões é possível explorar um dos questionamentos mais recorrentemente direcionados à abordagem histórica do tempo presente, que se refere à proximidade temporal dos pesquisadores em relação aos seus objetos. Para Certeau, há limites intransponíveis que separam as dimensões do real como prática passada que é conhecida pelo historiador e enquanto aquilo que remete a uma narrativização que busca conferir sentido a esse real. Conclui-se que as proposições de Certeau permitem pensar que no espaço configurado pela distância perene e constituinte da operação histórica, não há um objeto mais ou menos recente que interfira no fazer histórico, pois o historiador sempre escreve na verossimilhança do presente, o que faz com que a escrita histórica só seja contemporânea dela mesma.
\end{abstract}

Palavras-chave: CERTEAU, Michel de, 1925-1986. Tempo Presente. Operação Historiográfica.

\author{
Angélica Pall Oriani \\ Doutora em Educação pela Universidade \\ Estadual Paulista Júlio de Mesquita Filho, \\ (UNESP). Estágio Pós-Doutoral na \\ Universidade de São Paulo (USP). \\ São Paulo - BRASIL \\ angelicaoriani@hotmail.com
}

\section{Para citar este artigo:}

ORIANI, Angélica Pall. Primeiros rascunhos: aproximações entre Michel de Certeau e a História do Tempo Presente. Tempo e Argumento, Florianópolis, v. 9, n. 22, p. 316 - 338, set./dez. 2017.

DOI: $10.5965 / 2175180309222017316$

http://dx.doi.org/10.5965/2175180309222017316 


\title{
First drafts: approximations between Michel de Certeau and the History of the Present Time
}

\begin{abstract}
In a purposeful way, this text aims to establish approximations between Michel de Certeau's reflections about the historiographical operation and the history of the present time. The structure of this text marks the reflexive tone that guides it: initially, are presented Michel de Certeau's propositions about the historiographical operation, that materialize in a working and a writing; in sequence, are presented the reflections that seek in the discussions about the epistemology of distance and the historical story the points in which it's possible to face the theoretical and methodological dilemmas of history of the present time. Through these discussions it was possible to explore one of the questions which are recurrently directed to the history of the present time approach that refer to the chronological proximity that ties researchers to their objects. In Certeau's point of view there are insurmountable boundaries that separate the real dimension as a practice in the past that historians get to know, and as something that refer to a narrative process that intend to grant meaning to this real. It can be concluded that Certeau's ideas make possible to think that in the space characterized by a longstanding distance that compose the historiographical operation there is no more recent or less recent event that interfere in the history making, because the historian is always writing in the likelihood of the present, which means that writing history is a practice only contemporary to itself.
\end{abstract}

Keywords: CERTEAU, Michel de, 1925-1986. Present Time. Historiographical Operation. 
Vitrola
Há muito tempo, o cantor está morto
Mas sua voz, presa num disco,
ergue, em plena sala,
sua presença vívida.
*
E uns pensam:
"Como é bom poder ouvi-lo ainda,
Depois de tanto tempo!"
E outros pensam:
"Por que, depois de tanto tempo,
Fazê-lo ainda cantar!"

E o disco fantasma vai rodando.

Cecília Meireles (1958)

\section{Sobre o surgimento de uma dúvida}

Aprendi nas escolas de ensino fundamental e médio que a história é a ciência que estuda tempos remotos e aprendi isso de diversas formas: com a organização do conteúdo que acompanhava a divisão cronológica iniciando-se na distante "pré-história", passando pela "história antiga", pela "história da idade média" e terminando em uma "história contemporânea", a qual tinha como marco a eclosão da Segunda Guerra Mundial (1939-1945) e com o encerramento do conteúdo de história do Brasil, cuja demarcação era a implantação e a derrocada da ditadura militar (1964-1985), por exemplo.

Na faculdade, especialmente no Mestrado e no Doutorado em Educação, a ideia da história como campo de conhecimento que estudaria objetos situados em tempos antigos continuou pairando sob a obviedade e não mobilizou em mim nenhuma necessidade de demarcação específica, já que as relações entre passado e presente não incidiam de modo acentuado no direcionamento da análise dos meus objetos de pesquisa, situados no início do século XX.

A questão da proximidade temporal em que eu, pesquisadora, e o meu objeto de pesquisa se situavam se avultou como elemento catalisador de dúvidas durante as etapas 
de elaboração do projeto de pós-doutorado que iniciei no segundo semestre de 2016 na Faculdade de Educação (FE) da Universidade de São Paulo (USP).

Nesse projeto, analiso as estratégias políticas educacionais do Estado de São Paulo no que se refere à expansão e à manutenção das escolas rurais, no período entre 1967 e 1989. Meu recorte temporal, que se justifica em razão da elaboração e da implantação de projetos e planos educativos específicos, se situa cronologicamente em um período do qual eu sou contemporânea'

Eis, então, que surgiram algumas questões que venho enfrentando desde que iniciei as minhas atividades do pós-doutorado: como problematizar e circunscrever teoricamente e metodologicamente a abordagem² da história do tempo presente? Quais são os aspectos que a diferenciam da história com a qual eu havia trabalhado até então? Como ela vem sendo proposta por aqueles que a utilizam em seus estudos?

Este texto busca concentrar meus primeiros rascunhos teóricos esboçados no sentido de concretizar minhas problematizações ao situar meu trabalho dentro dessa abordagem. Para tal, devo indicar que o ponto de onde escolhi partir para apresentar minhas elucubrações está assentado na própria epistemologia da história; isso significa que o caminho que optei percorrer no sentido de buscar elementos que me permitissem pensar a respeito dessa abordagem foi o de pensar sobre o próprio fazer história.

Quando escolhi o caminho da problematização do fazer história, delimitei Michel de Certeau $^{3}$ como meu principal interlocutor em razão de suas discussões a respeito da

\footnotetext{
${ }^{1}$ A reflexão em torno do conceito de contemporâneo está intimamente interligada com a questão temporal e, por si só, já oferece um conjunto de questões pertinentes acerca das dimensões temporais e circunstanciais a respeito dos limites do contemporâneo. De quem eu, como pesquisadora, poderia ser considerada contemporânea? Qual a relação que estabeleço com o meu tempo que endossaria a afirmação da contemporaneidade de minhas práticas? Essas questões, como se percebe, são intrigantes, porém, em razão dos limites de extensão e da definição da proposta do texto, não fazem parte do escopo deste trabalho; em todo caso, deixo-as registradas como prenúncio das discussões que ainda precisam ser levadas mais adiante em relação a essa temática.

2 Pelas minhas incursões iniciais em leituras a respeito da história do tempo presente, constatei dissonância em relação a sua denominação; ora li enfoque, ora abordagem, ora vertente. Optei por manter neste texto a história do tempo presente sob a designação abordagem.

3 Em paralelo às minhas atividades do pós-doutorado, cursei a disciplina oferecida pela Profa ${ }^{2}{ }^{a}$ Diana Gonçalves Vidal na FEUSP, intitulada "Michel de Certeau: entre história e educação" e, por meio dessa disciplina pude refletir sobre a abordagem desse autor acerca da operação historiográfica e sobre os modelos metodológicos de análise das práticas ordinárias que ele propõe.
} 

cruciais para a história do tempo presente.

Este texto é o resultado dessa interlocução. Sua organização corresponde aos caminhos de minha reflexão. Inicio apresentando as propostas de Michel de Certeau a respeito da operação historiográfica que se concretiza em um fazer e em uma escrita e, na sequência, estão os resultados de minhas reflexões que buscam no diálogo com esse autor os pontos nos quais há possibilidade de enfrentar os dilemas teóricometodológicos da história do tempo presente.

\section{Fazer história ou a construção do túmulo para um passado morto}

"O discurso sobre o passado tem como estatuto de ser o discurso do morto" (CERTEAU, 2002, p. 55). É de forma incisiva e propositiva que Michel de Certeau apresenta problematizações no livro que contém suas reflexões epistemológicas acerca d'A escrita da história, editado na França, em 1975, e publicado no Brasil pela Forense Universitária, em 1982.

De acordo com Vidal (2005), em A escrita da história, Certeau amplia as discussões que havia iniciado em A operação historiográfica, texto que constituiu capítulo inicial do livro História: novos problemas, organizado por Jacques Le Goff e Pierre Nora, publicado na França, em 1974, e no Brasil, em 1976, e que concretizava os anseios dos historiadores a respeito das incertezas e das dúvidas em relação aos aspectos epistemológicos e sociais da disciplina História 4 .

\footnotetext{
${ }^{4}$ De acordo com Vidal (2005, p. 277-278), a "[...] conscientização pelos historiadores do relativismo de sua ciência (a história não é o passado, mas uma construção); a agressão sofrida das Ciências Sociais que propunham o modelo estatístico de análise como certificação de legitimidade científica; a ruptura com uma Filosofia da História evidenciada como necessária a partir de Foucault; a invasão do campo por outras ciências de fronteiras mal delimitadas como a Etnologia; a fragmentação e a dispersão dos objetos impondo a busca de novos paradigmas; além dos apelos a uma história do tempo presente, que colocavam em suspenso a concepção de história como ciência do passado, eram, de acordo com Le Goff e Nora (1974, p. 12-13), os novos desafios postos à disciplina que a obrigavam a se redefinir."
} 
Situando-se contrariamente às problematizações que restringiam os dilemas da história aos da narração, como Paul Veyne (1971), que lança mão da ideia de história como ficção ou como Hayden White (1973), que estabelece a história como narrativa, Certeau propõe partir do próprio fazer do historiador para pensar a história como prática científica e problematizar, em decorrência, "as premissas das quais o discurso não fala" e "as leis silenciosas que organizam o espaço produzido como texto" (CERTEAU, 2002, p. 65).

Eis, então, que Certeau (2002, p. 65 grifos do autor) propõe encarar a história como uma operação, compreendendo-a como a relação entre "[...] um lugar (um recrutamento, um meio, uma profissão etc.), procedimentos de análise (uma disciplina) e a construção de um texto (uma literatura)." A pesquisa historiográfica se articula em função de um lugar de produção social, econômico, político e cultural e isso organiza a preferência por determinados métodos, as convenções disciplinares, a hierarquia de interesses, a constituição de objetos de investigação e, também, a existência de "estranhas e vastas praias de silêncios" (REVEL; CERTEAU; JULIA, 1989, p. 67). Na relação entre as permissões e as interdições instauradas no campo, o discurso histórico é o produto de um lugar, estabelecido a partir das interações e combinações realizadas com os seus "outros discursos contemporâneos".

Certeau (2011) enfatiza que a relação dos enunciados científicos com os lugares de onde eles advêm confere estatuto hierárquico aos discursos. Assim, ao invés de crer na escrita, acredita-se de fato na instituição que determina o seu funcionamento e que garante a credibilidade do suposto saber do texto: "Retirem o título de professor ao autor de um texto histórico: ele limita-se a ser um romancista" (CERTEAU, 2011, p. 113).

Por esse motivo, reconhecer que a história é configurada pelo sistema no qual se elabora permite compreender a "[...] ligação entre uma prática interpretativa e uma prática social" (VIDAL, 2005, p. 278), e esse reconhecimento, apesar de não explicar a história, permite analisar a sociedade e ser condição de que o dito não seja legendário ou impertinente. 
Ao se apoiar em um conjunto de elementos e procedimentos de análise, a história é uma operação científica à medida que "[...] transforma o 'meio' - ou que faz de uma organização (social, literária etc.) a condição e o lugar de uma transformação" (CERTEAU, 2002, p. 79). Sobre esses procedimentos, Certeau (2002, p. 80) enfatiza que o primeiro ato em história é o "[...] gesto de separar, de reunir, de transformar em 'documentos' certos objetos distribuídos de outra maneira." Essa nova distribuição configura a produção dos documentos, pois Ihes seriam modificados o estatuto e o lugar: não se trata apenas de dar voz aos silêncios, mas de transformar alguma coisa que tinha sua "[...] posição e seu papel, em alguma outra coisa que funciona diferente" (CERTEAU, 2002, p. 82).

Como concretização da operação historiográfica, o discurso histórico ${ }^{5}$ permite a passagem da prática investigadora a uma escrita. Nesse processo, o discurso impõe algumas servidões à pesquisa: a inversão da ordem da pesquisa - prescrevendo como início aquilo que havia sido o ponto de chegada do estudo; o encerramento do texto por mais que a pesquisa seja interminável, o texto precisa ter um fim; e a substituição de um trabalho de lacuna por uma presença de sentido ${ }^{6}$ - ela dá lugar à falta e a esconde, "exorciza e reconhece uma presença de morte no meio dos vivos" (CERTEAU, 2002, p. 94).

\footnotetext{
${ }^{5}$ Apoiando-se nas distinções de Émile Benvéniste (1966 apud CERTEAU, 2002) a respeito de "discurso" e de "relato", Certeau (2002, p. 96 grifos do autor) afirma que a historiografia é "[...] um relato que funciona, na realidade, como discurso organizado pelo lugar dos 'interlocutores' e fundamentado no lugar que se dá o 'autor' com relação aos seus leitores." Para o linguista francês Benvéniste, enquanto no discurso a instância está na ação e no ato da palavra dos interlocutores, no relato, a instância se situa nos tempos que se referem a objetos reais, aos tempos e aos lugares históricos. Abordarei pontualmente as problematizações de Certeau a respeito do relato na sequência.

6 Em "O Ausente da história", capítulo originalmente publicado como conclusão em uma coletânea homônima em 1973, inserido em História e psicanálise: entre ciência e ficção, saída a lume na França, em 1987, e no Brasil, em 2011, pela Autêntica, Certeau (2011) de certo modo prenuncia as questões que desenvolveria n'A escrita da história e reflete sobre a existência de uma ausência que a história pretenderia esconder ao preencher lacunas no discurso que organiza. Certeau (2011, p. 188) afirma que a "[...] narrativa começa a falar entre contemporâneos. Parece-me que ela pode falar do sentido que se tornou possível pela ausência quando não existe outro lugar além do discurso. Ela diz, então, algo relacionado com qualquer comunicação, mas elabora tal relato sob a forma de lenda - a bom entendedor, meia palavra basta -, em um discurso que organiza uma presença faltante (CERTEAU, 2011) e conserva, do sonho ou do lapso, a possibilidade de ser a marca de uma alteridade alterante."
} 
Considerada como uma combinação entre a narração e o discurso lógico (VIDAL, 2005), o discurso histórico para Certeau (2002) é produzido a partir de dois movimentos contrários:

[...] uma narrativização faz passar do conteúdo à sua expansão, de modelos anacrônicos a uma cronologização, de uma doutrina a uma manifestação de tipo narrativo; inversamente, uma semantização do material faz passar dos elementos descritivos a um encadeamento sintagmático dos enunciados e à constituição de sequências históricas programadas. (CERTEAU, 2002, p. 100 grifos do autor)

Nesse sentido, o caráter metafórico, empregado no sentido aristotélico como operação que permite "a passagem de um gênero a outro" (CERTEAU, 2002, p. 100) está presente no discurso histórico, pois reorganiza a causalidade como sucessividade e representa relações de coexistência como de coerência. Além disso, há alguns outros desdobramentos que se coadunam para a produção do texto historiográfico: a organização do texto como um discurso folheado e as unidades de sentido que formariam "[...] o tabuleiro de uma exposição onde cada compartimento deve ser preenchido."

Segundo Certeau (2002), a exigência das citações, das referências e das notas de rodapé confere credibilidade ao discurso. Pelas citações, o texto se estabelece como saber do outro. Na encenação historiográfica, as citações introduzem a relação entre um lugar de saber e sua exterioridade, elaboram um "contrato enunciativo entre o remetente e o destinatário" e produzem um tipo de leitor: "[...] um destinatário citado, identificado e doutrinado pelo próprio fato de estar colocado na situação da crônica diante de um saber" (CERTEAU, 2002, p. 101).

As categorias de sentido oferecem inteligibilidade ao discurso, compõem um conjunto coerente de unidades que assegura certo número de recortes semânticos que são abarcados sob a chancela de categorias históricas. Essas unidades semeiam certa desordem na ordem estabelecida pelos conceitos e à medida que constroem uma unidade de sentido, a erodem: o discurso é histórico para Certeau (2002) à medida que o 
trabalho movimenta e corrói o aparelho conceitual e essa operação é necessária para o estabelecimento textual que se abre a esse movimento ${ }^{7}$.

Há que se considerar, também, outro aspecto crucial para o entendimento da proposição epistemológica da história para Certeau, que é a compreensão de que a história é o discurso do morto e que a escrita coloca em cena uma população de mortos, não apenas para honrá-los, mas para exorcizá-los e eliminá-los. Por esse motivo, então, que, em um sentido etnológico, a escrita representaria o rito de sepultamento dos mortos. Esse ritual compreenderia algumas funções.

Por um lado, tem função simbolizadora; permite a uma sociedade situarse, dando-lhe, na linguagem, um passado, e abrindo assim um espaço próprio para o presente: "marcar" um passado é dar lugar à morte, mas também redistribuir 0 espaço das possibilidades, determinar negativamente aquilo que está por fazer e, consequentemente, utilizar a narratividade, que enterra os mortos, como um meio de estabelecer um lugar para os vivos. A arrumação dos ausentes é o inverso de uma normatividade que visa o leitor vivo, e que instaura uma relação didática entre o remetente e o destinatário. (CERTEAU, 2002, p. 106. Grifos do autor)

Nesse sentido, a exumação e a eliminação dos mortos possibilita a abertura de espaço para que se articule o que surge com o que desparece: "Nomear os ausentes da casa e introduzi-los na linguagem escriturária é liberar o apartamento para os vivos, através de um ato de comunicação, que combina a ausência dos vivos na linguagem com a ausência dos mortos na casa" (CERTEAU, 2002, p. 107).

Por esse motivo, para Certeau, a relação com a linguagem permite a uma prática se situar em relação ao seu passado, esse outro que se conhece. Todavia, é a partir das leis do presente que a historiografia efetua uma redistribuição dessas práticas já semantizadas, combinando na encenação literária o desejo de exorcizar que constitui a sua relação com o outro.

\footnotetext{
7 Para Certeau (2002, p. 105), o "[...] trabalho que desloca o lugar e o associa àquilo de que estava separado, esboça no texto um desparecimento (nunca total) dos conceitos, como se ele conduzisse a representação (sempre mantida enquanto exista texto) até a beira da ausência que ela designa."
} 
Se, porém, o objeto que circula no discurso histórico é o morto, é um ausente, o sentido do discurso é o de ser uma ponte de comunicação entre os vivos, os presentes: o autor e o leitor do texto. Isso significa que o morto é a "figura objetiva" da troca entre vivos, é o "[...] enunciado do discurso que o transporta como objeto, mas em função de uma interlocução remetida para fora do discurso, no não-dito" (CERTEAU, 2002, p. 55 grifos do autor).

O discurso historiográfico é para Certeau, portanto, um dizer que se articula com algo para além dele, que trata a morte como um objeto de saber, que se inicia a partir de um objeto perdido e morto, cuja representação funciona a partir de uma cena primitiva, ainda organizadora apesar de apagada.

Por fim, é pertinente destacar a síntese de Certeau (2002, p. 57):

Esta é a história. Um jogo da vida e da morte prossegue no calmo desdobramento de um relato, ressurgência e denegação da origem, desvelamento de um passado morto e resultado de uma prática presente. Ela reitera em um regime diferente os mitos que se constroem sobre um assassinato ou uma morte originária, e que fazem da linguagem o vestígio sempre remanescente de um começo tão impossível de reencontrar quanto de esquecer.

\section{Uma clivagem necessária - encontrar o presente nos objetos e o passado nas práticas}

As proposições de Michel de Certeau a respeito da operação histórica iluminam uma série de debates que a história do tempo presente enfrenta. Para iniciar a exposição é pertinente situar o leitor acerca do surgimento dessa abordagem ${ }^{8}$, que remete ao período pós Segunda Guerra Mundial e à criação do Institut d'histoire du temps présent (IHTP), fundado, na França, em 1978 e inaugurado em 1980, como uma unidade própria de pesquisa do Conseil National de Recherches Scientifiques (CNRS).

\footnotetext{
${ }^{8} \mathrm{~A}$ abordagem que conferi ao surgimento e aos principais dilemas da história do tempo presente é concisa em razão dos objetivos que propus a este texto. Para maiores detalhamentos, conferir especialmente: Chauveau e Tétart (1999); Dosse (2012); Fico (2012); e Sirinelli (2004).
} 
A criação desse instituto de pesquisa acompanhou certo movimento de redefinição epistemológica no âmbito da comunidade de historiadores em face das demandas que se avultaram após a Segunda Guerra Mundial decorrentes da necessidade de repensar alguns referenciais históricos. Em meio à necessidade de armazenar documentos resultantes de eventos traumáticos, alguns historiadores franceses passaram a refletir acerca da relação que estabeleciam com o passado e com o futuro, no que se refere à preservação da memória e do patrimônio e à elaboração de políticas de conservação documental e arquivística, o que implicava, também, problematizar a ideia de previsibilidade em um futuro esfacelado e realocar a visão e o lugar que o passado ocupava no imaginário contemporâneo (MULLER, 2007).

No âmbito desse laboratório de pesquisa, portanto, foram catalisadas discussões a respeito: do papel do relato testemunhal como um elemento de grande pertinência para a compreensão dos conflitos e, portanto, admitiu-se a "ascensão da dimensão memorial na história" (DOSSE, 2012); das metodologias e fontes que serviriam aos propósitos dessa nova forma de conduzir pesquisas, as quais utilizam fontes orais; das questões éticas e morais que estão envolvidas quando o historiador traz à tona demandas delicadas e que incidem diretamente na vida de pessoas ainda vivas $^{9}$ e, em paralelo, do papel dos historiadores no espaço público ${ }^{10}$; da busca da identidade da história e da sua associação com outras disciplinas fronteiriças das Ciências Sociais; da crescente incerteza a respeito das dimensões temporais do presente e do futuro; e do retorno da história política, que,

9 A respeito dessas incidências, em "História do Tempo Presente, eventos traumáticos e documentos sensíveis: o caso brasileiro", Fico (2012) discute questões teóricas dessa abordagem e relata duas situações que enfrentou, as quais exemplificam a situação de tensão ético-moral que o pesquisador pode enfrentar. Na primeira situação, Fico (2012) narra que durante uma palestra foi contestado por uma ex-militante da esquerda que não concordava com o tom heroico endossado pela fala desse professor às narrativas da luta armada, calando-o ao assinalar: "Eu fui torturada!" (FICO, 2012, p. 48). Na segunda situação, Fico relata que ao entrevistar um militar, o flagrou quando ele afirmou que o Al-5, decretado em 1968, veio depois do sequestro do embaixador norte-americano, ocorrido em 1969. Fico (2012) analisa que o testemunho verdadeiro do primeiro relato interditou o debate e a "falsa memória" do general forneceu a ele, pesquisador, uma compreensão da trajetória do entrevistado, não necessariamente arraigada a essa mentira pontual, mas vinculada à construção de uma cronologia adequada que lhe confortasse e justificasse as suas percepções a respeito do caso.

${ }^{10}$ Fico (2012, p. 47) relata que o historiador francês Henry Rousso optou por "[...] não atuar como perito e recusou-se a testemunhar diante do tribunal que julgou, no final de 1997 e início de 1998, Maurice Popon, acusado de colaboracionismo com o regime de Vichy." E questiona se com a então recente instalada Comissão da Verdade no Brasil, os historiadores deveriam ser convidados a participar de iniciativas desse tipo, as quais, quase sempre geram uma narrativa única. 
nas décadas iniciais do século XX, havia sido desvalorizada e negligenciada pela tradição francesa, por ter sido entendida como história-batalha, tradicional, factual, e substituída pela história econômico-social quantitativa de média e longa duração pelo grupo da revista Annales (GLEZER, 2007).

Como se observa, a própria mudança na noção do tempo e do espaço de atuação científica que afetou a percepção do presente, do passado e do futuro: o objeto da análise não repousaria somente naquilo que aconteceu, mas naquilo que poderia ser retido, pensando em alguma forma de intervenção.

Conforme afirma Glezer (2007, p. 39), as atividades do IHTP não foram muito pontuais no sentido de produzir trabalhos teóricos a respeito do tempo presente, concentrando-se, ao longo dos anos, nas questões do interesse de uma história política renovada para os assuntos culturais, movimento que caminhou em paralelo ao da pesquisa histórica de uma forma geral a partir dos anos 1980. Por meio dessas intersecções com as questões culturais, surgiu a possibilidade de valorização das diferenças e das experiências pontuais e, em contraposição, as questões a respeito da dimensão temporal propriamente dita acabaram sendo deixadas de lado.

Os desdobramentos que as mudanças da história do tempo presente acarretaram para a pesquisa científica se concentram na própria noção de tempo e de temporalidade e nos limites que demarcariam o início do tempo presente ${ }^{11}$.

Dosse (2012) traz ao debate elementos importantes ao discutir de que modo as incertezas sobre o futuro acabaram por alterar nossa relação com o presente e com o passado. Os dilemas acerca da presença de um passado no espaço público, de uma crise a

\footnotetext{
11 Sob esse ponto de vista, vale registrar a arbitrariedade do desmonte e do remonte da operação historiográfica acerca das delimitações cronológicas. Dito de outro modo, o ponto crucial da reflexão é o próprio registro do que é o presente ou contemporâneo e o limite da definição "presente" que qualifica o "tempo" da história e a separa da "tão-somente" história. Como o leitor deve ter observado, a história do tempo presente não trata daquilo que é diretamente mais próximo do ponto de vista cronológico e temporal do historiador, porém, os limites acerca dessa separação ainda são pouco explorados. Dosse (2012) exemplifica essas questões trazendo as propostas de alguns pesquisadores acerca desses limites, muitos dos quais restritos a grandes situações de colapsos, como a Segunda Guerra Mundial e a queda do muro de Berlim, por exemplo. Uma das possíveis incursões nessas veredas dos limites cronológicos é problematizar o sentido do contemporâneo e, ao fazê-lo, pensar nesse regime de historicidade mais como um espaço de experiência que atravessa o presente e o passado e se situa em uma relação singular com o próprio tempo e dele toma distâncias.
} 
respeito de um futuro não passível de previsão, de um desaparecimento gradual de uma "cronosofia" que daria sentido à "flecha do tempo" deslocaram a atenção para o momento da realização da ação e, com isso, o presente se tornou o detentor do sentido articulado à memória, à comemoração, à preservação, ao patrimônio e à retenção arquivística.

Todas essas dimensões que se referem à relação social com o tempo impactam diretamente as formas a partir das quais os historiadores passaram a investigar seus objetos: o eixo que partiria das buscas pelas causas remotas dos fenômenos históricos, conferindo certa distância e cadência à explicação histórica envereda para as indeterminações dos fatos, para os traços, para os vestígios e para as disjunções.

Em paralelo a essa relação, a questão da proximidade temporal é um dos aspectos recorrentemente mencionados entre os pesquisadores dessa abordagem. Chartier (1993) afirma que na história do tempo presente, o pesquisador é contemporâneo de seu objeto e divide, portanto, as mesmas categorias e referências com aqueles que investiga. Assim, a falta de distância, ao invés de ser um inconveniente, pode ser um instrumento de auxílio importante para um maior entendimento da realidade estudada, de maneira a superar a descontinuidade fundamental, que ordinariamente separa o instrumental intelectual, afetivo e psíquico do historiador e o daqueles que são objetos de pesquisa.

Para Dosse (2012), essa questão pode ser problematizada do ponto de vista da subjetividade do historiador. Esse autor aponta os resultados das reflexões de Pierre Nora em seu projeto sobre a "ego história", iniciado em meados de 1980, como catalisadores de uma mudança historiográfica que ampliou o conceito de tempo presente, não concebido necessariamente como algo mais próximo do pesquisador. 0 conceito remete

[...] em sua acepção extensiva ao que é do passado e nos é ainda contemporâneo, ou ainda, apresenta um sentido para nós do contemporâneo não contemporâneo. A noção de "tempo presente" se torna nesse contexto um meio de revisitação do passado e de suas possíveis certezas, como também as possíveis incertezas. A distância temporal que nos separa do passado se transforma, porque até então considerada uma desvantagem, ela se transforma em uma sedimentação de camadas sucessivas de sentido que expandem seu alcance graças à maior profundidade. (DOSSE, 2012, p. 11-12. Grifo do autor) 
Por esse motivo, Dosse (2012, p. 6. Grifo do autor) defende que a verdadeira singularidade da história do tempo presente reside na "[...] contemporaneidade do não contemporâneo, na espessura temporal do 'espaço de experiência' e no presente do passado incorporado."

As inflexões se assentam, portanto, na não-negação de certa participação do historiador e, em contrapartida, na valorização dos elementos que conferem unidade a um tipo de análise que pode estar dialogando com o não contemporâneo no contemporâneo ou com o seu inverso.

Buscando nas proposições de Heller (1993 apud MULLER, 2007) alguns caminhos para refletir acerca da relação de proximidade e de distância com o tempo passado e presente, Muller (2007, p. 28. Grifos da autora) pontua a história como construção mental que não tem fronteiras. Desse ponto de vista, existiria história e apenas história, pois "a melhor história do tempo presente seria aquela escrita no nosso tempo, a partir dos saberes, das ideias, da cultura de nosso tempo."

Por fim, outro aspecto recorrentemente citado nos textos que problematizam a história do tempo presente se refere à relação entre história e memória e ao uso da história oral ${ }^{12}$.

Ferreira (2002) argumenta que foi principalmente a partir do interesse dos pesquisadores franceses acerca das mentalidades coletivas que o papel da memória passou a ser encarado de outra forma. Nesses estudos, a cultura popular, a vida familiar e os hábitos locais emergiram como temáticas atravessadas pela análise das questões da formação de uma memória coletiva.

\footnotetext{
${ }^{12}$ Segundo Ferreira (2002), há muitos questionamentos a respeito do uso da expressão "história oral" em favor de "fontes orais". A principal crítica à expressão "história oral" liga-se ao fato de que não existem discursos orais puros e de que esses discursos só ganhariam legitimidade em confronto com um documento escrito. Critica-se, também, a noção de que a história oral seria outra história, mais "[...] comprometida com a militância política do que com o rigor dos métodos acadêmicos." (FERREIRA, 2002, p. 329). Em contrapartida, o uso da expressão "fontes orais", que parece encontrar mais adeptos, não exigiria tanta preparação prévia por parte do pesquisador e equivaleria a uma fonte produzida pelo historiador como de qualquer outro tipo, o que revelaria, segundo Ferreira (2002), mais uma desvalorização do método da história oral.
} 
Nesse caminho, alguns trabalhos promoveram a crescente valorização da história das representações, do imaginário social e certos estreitamentos entre a memória e a história, como o do historiador Phillipe Ariès sobre o papel dos rituais comemorativos durante o final do século XVIII e início do XIX, o do sociólogo Maurice Halbwachs a respeito da memória como uma relação entre repetição e rememoração e o do historiador Pierre Nora acerca das políticas de memórias coletivas na França. Com isso, pesquisadores retomaram a possibilidade de avaliar o papel da memória no entendimento das questões da história.

Segundo Ferreira (2002, p. 321), é Pierre Nora que aprofunda a discussão a respeito da distinção entre o relato histórico e o discurso da memória, quando sintetiza que a história produz "[...] um conhecimento racional, uma análise crítica de uma exposição lógica dos acontecimentos e vidas do passado. A memória é também uma construção do passado, mas pautada em emoções e vivências; ela é flexível, e os eventos são lembrados à luz da experiência subsequente e das necessidades do presente."

Com isso, abriram-se possibilidades para utilizar os testemunhos diretos na produção de conhecimento histórico, mesmo reconhecendo a subjetividade, as distorções dos depoimentos e as possíveis faltas de veracidade ou de confusão nesses documentos produzidos. A história oral evidencia-se, nesse processo, como "[...] instrumento privilegiado para recuperar memórias e resgatar experiências de histórias vividas" (FERREIRA, 2002, p. 326).

Diante do que apresentei anteriormente, o ponto que mobiliza grande parte de minhas reflexões se refere à dificuldade de estabelecer os limites entre um discurso histórico que explicita um passado do qual eu, pesquisadora, sou contemporânea.

Busquei nas reflexões de Certeau (2002) alguns elementos que pudessem fornecer subsídios teóricos para pensar sobre esses enfretamentos e, nesse movimento, identifiquei nas discussões desse autor a respeito das dimensões do real enquanto aquilo que é conhecido pelo historiador, e enquanto aquilo que remete a uma prática de sentido, uma das possíveis formas de problematizar o trabalho no âmbito da abordagem da história do tempo presente. 
Além dessas discussões, a proposição de Certeau (2002; 1985) acerca do relato histórico como narrativização de uma prática passada, como concretização da sequência da prática e como cadenciamento das ações em uma estrutura cronológica e organizacional fornece alguns elementos necessários para discutir a questão da epistemologia da distância, que se refere ao espaço impreenchível que existe entre relato e prática.

Segundo Certeau (2002), como prática, o discurso historiográfico remete a uma realidade e explicita a sua identidade social a partir da diferenciação que opera entre o "eu" e "outra época" ou "outra sociedade"; essa diferenciação, que não é estável e busca essa relação com as origens - sejam elas próximas ou distantes -, estabelece o lugar da história como ciência.

Para esse autor, o "real" representado na historiografia não corresponde ao real que determina a sua produção. Ele esconde "[...] por trás de uma figuração de um passado, o presente que o organiza" (CERTEAU, 2011, p. 49). Nessa fronteira entre o real como prática de uma inteligibilidade e o real como algo a ser conhecido que o historiador se situa (DOSSE, 2004).

Por isso, em vez de representar um passado, o texto historiográfico procede à elucidação da operação institucional que o fabrica. Essa narrativa que fala em nome do real faz conhecer à "maneira como se dá uma ordem." (CERTEAU, 2011). Com isso, não é possível ao historiador escapar dessas articulações que emaranham o passado e o presente. Ele não pode "[...] fazer abstração dos distanciamentos e das exclusividades que definem a época ou a categoria social à qual pertence. Em sua operação as permanências ocultas e as rupturas instauradoras formam amálgama" (CERTEAU, 2002, p. 47).

Apesar de estar amparado pelo corte que separa um passado, que é objeto, e um presente, que são as práticas, o historiador quando retorna a estas e as examina a fim de renová-las, descobre "[...] imposições que se originaram bem antes do seu presente e que remontam a organizações anteriores, das quais seu trabalho é o sintoma e não a fonte." Por esse motivo, a "[...] história não para de encontrar o presente no seu objeto, e o 
O relato histórico articula, portanto, a "[...] prática de uma nova inteligibilidade e a remanescência de passados diferentes (que sobrevivem, não apenas nos documentos, mas nesse 'arquivo' particular que é o próprio trabalho histórico)" (CERTEAU, 2002, p. 55). Para Dosse (2004, p. 196), ao operar com esses limites, Michel de Certeau situou a operação historiográfica "[...] em um espaço intermediário localizado entre a linguagem de ontem e a linguagem contemporânea do historiador."

Há que se destacar que a relação com um ausente, com um "outro" implica o movimento de retorno desse outro à historiografia. Para Certeau (2011), essa combinação do retorno do passado no discurso do presente seria o "próprio"13 histórico. Essa mistura agita o corte operado pela historiografia entre um presente e um passado distintos, "[...] em que um é 'sujeito' e o outro 'objeto' de um saber, um é produtor do discurso e o outro representado. De fato, esse ob-jeto, ob-jectum - supostamente, exterior ao laboratório determina a partir de dentro suas operações" (CERTEAU, 2011, p. 62. Grifos do autor).

Ao analisar essa questão do retorno do ausente ao discurso historiográfico, Dosse (2004) indica que é na

[...] pluralidade das sedimentações de sentido depositadas na espessura do passado que se encontra o enigma sempre presente de um acesso ao real que tem de fato, em Certeau, essa dimensão limite da restituição de uma figura perdida, como em Lacan, que atribuía ao Real o lugar do impossível. O real está irremediavelmente na posição do ausente por toda parte suposto e por toda parte faltante. Contudo este ausente está ali, aninhado dentro do próprio presente, não como aquele que perdura em uma espécie de estufa esperando ser objeto de atenção periódica, mas acessível à legibilidade graças às sucessivas metamorfoses que sofre em uma inversão perpetuada ao longo do tempo de acontecimentos antigos reconfigurados a cada vez. Nesse ponto, Certeau atribui uma prevalência a relação cambiante instituída pelo presente com seu passado. (DOSSE, 2004, p. 213-214. Grifos do autor)

\footnotetext{
${ }^{13}$ Para Certeau, o "próprio" representa o presente de uma prática.
} 
Por esse motivo, a história deve ser concebida como um rasgo temporal incessante, como uma dobra na temporalidade. "Não há nenhuma hierarquização nesse tempo folheado, pois cada um de seus instantes de reatualização é em si uma 'ruptura instauradora' que torna suas consequências incomparáveis ao que a precede" (DOSSE, 2004, p. 215 grifo do autor).

Com esses elementos, é possível desmistificar certa avaliação de comprometimento ou de envolvimento passional que poderia enviesar e enformar a prática do historiador em face de objetos de pesquisa a ele contemporâneos. Há, segundo Certeau (2002; 2011), uma região fronteiriça entre um passado, pretensamente enclausurado em si, e um presente com práticas imaculadas; passado e presente se articulam, se atenuam e se modificam continuamente e à medida que o historiador demarca os limites entre o "eu" e o "outro", esse outro retorna ao discurso.

Dosse (2004, p. 108. Grifos do autor) apresenta discussões que endossam essa perspectiva e afirma que a

[...] descontinuidade que opõe nosso presente ao passado torna-se então uma vantagem para desenvolver uma nova consciência historiográfica: "A distância temporal não é portanto um obstáculo a superar [...] o importante, na realidade, é ver na distância temporal uma possibilidade positiva e produtiva que é dada a entender" [...]

Nessas situações de limites, descontinuidades e regiões fronteiriças, o relato como gênero literário próprio ao discurso historiográfico pode ser encarado como elemento crucial. Para Certeau (2002), o relato histórico cria a possibilidade de tornar os contrários coerentes entre si, a partir da temporalização que um texto narrativo efetiva.

A temporalização cria a possibilidade de tornar coerentes uma "ordem" e o seu "heteróclito". Com relação ao "espaço plano" de um sistema, a narrativização cria uma "espessura" que permite colocar, ao lado do sistema, o seu contrário ou o seu resto. Uma colocação em perspectiva histórica autoriza, pois, a operação que no mesmo lugar e no mesmo texto, substitui a disjunção pela conjunção, reúne enunciados contrários e, mais amplamente, supera a diferença entre uma ordem e aquilo que ela exclui. É também o instrumento por excelência de todo discurso que 
Nesse sentido, a cronologia e a exposição histórica transformam o sentido do percurso atribuindo ao texto um novo "espaço vetorial", condição de tornar possível a articulação da prática com a escrita. É por esse motivo que Certeau (2002, p. 97. Grifo do autor) enfatiza o presente como "[...] a renda da operação escriturária: o lugar de produção do texto se transforma em lugar produzido pelo texto." A historiografia trabalha, assim, para encontrar esse presente que é o término do percurso do seu objeto em uma trajetória cronológica.

Por intermédio de seu mecanismo organizador, o relato ${ }^{14}$ permite dar precisão a uma referência inicial e imperceptível, condição de sua historicização e temporalização, e permite também que o presente "exista no tempo" (CERTEAU, 2002). Isso porque ele segue a cadência da prática e está mais próximo da prática, justamente pelo fato de a escrita operar a partir da inversão escriturária.

Como é possível observar, o espaço entre a prática e o relato da prática (a escrita historiográfica) constitui elemento fundador de uma distância instransponível para o pesquisador, já que a prática sempre se localiza no passado e a escrita sempre no presente; o que faz com a escrita só seja contemporânea dela mesma.

\footnotetext{
${ }^{14}$ Ao analisar as produções cotidianas dos homens comuns, Certeau (1985) apresenta modelos teóricos e metodológicos por meio dos quais essas práticas poderiam ser captadas. Um dos modelos apresentados por Certeau (1985, p. 18) é o relato, que, como discursividade funciona como uma teoria da prática cotidiana, por ser, em si, uma prática cotidiana: "[...] ele é o único tipo de texto que é, ao mesmo tempo, uma discussão das práticas cotidianas e uma prática cotidiana em si. Ele próprio constitui a teoria daquilo que faz, daquilo que conta." Em "Teoria e método no estudo das práticas cotidianas", texto que resulta de palestra que Certeau (1985) proferiu na Faculdade de Arquitetura e Urbanismo (FAU) da USP em 1985, esse autor assinala, no entanto, que ainda se fazia necessária uma teoria da narrativa para elaborar um discurso sobre as práticas cotidianas, para poder "[...] elaborar um estatuto e normas do discurso, uma maneira de tratar os materiais existentes sobre as práticas cotidianas [...] ou de como analisar o relato das práticas cotidianas" (CERTEAU, 1985, p. 18-19).
} 
No espaço configurado por essa distância perene e constituinte da operação histórica, não há um mais recente ou um menos recente que interfira no fazer histórico, pois, devido às características teórico-metodológicas da historiografia, o historiador sempre escreve na verossimilhança do presente. Desse modo, dentro do ponto de vista de Certeau, para a historiografia, independentemente de o objeto de pesquisa se situar no "tempo presente" ou no um "tempo passado", sempre haverá esse encontro, necessário e inexorável, entre o presente nos objetos e o passado nas práticas.

\section{Rasurando a relação com o tempo no instante de emissão da escrita no presente}

Este texto teve um caráter ensaístico e propositivo. Refleti sobre a epistemologia da história conforme proposta por Michel de Certeau para tecer algumas aproximações com a abordagem da história do tempo presente. Busquei nesse espaço de interlocução alguns elementos para pensar pontos que veem me mobilizando conceitualmente nos últimos meses.

De fato, as proposições de Certeau acerca da história como um fazer presente que opera sobre um passado movido por leis silenciosas que organizam o discurso criam a abertura necessária para pensar a atuação do historiador sempre em um limite, em uma relação desdobrada. Independente da "distância temporal" entre historiador e objeto de pesquisa, o espaço entre os dois será sempre marcado pela impossibilidade de o pesquisador relatar aquilo que de fato foi, porque a prática só é contemporânea à própria prática.

Para as reflexões que encerram este texto, quero tomar como exemplo o filme Amnésia, dirigido por Cristopher Nolan e lançado em 2001 com o título original Memento. O filme conta os percalços de um jovem que perdeu a habilidade de memorizar qualquer acontecimento recente para encontrar o assassino de sua esposa. Suas ações desesperadas para reter as informações à revelia de sua condição física incluíram o uso de fotografia, de um caderno de anotações e da tatuagem dos resultados de sua investigação em seu corpo, para que os detalhes que ele já havia recuperado não lhe escapassem. 
Trata-se de uma história comum. Mas a originalidade está no roteiro do filme, que encadeia as cenas seguindo outra sequência que não a linear e serial dos acontecimentos. A primeira cena do filme é o seu desfecho e a sequência é costurada de trás para frente junto aos flashes de memória do protagonista conduzindo o telespectador numa ordenação à marcha ré do tempo. O início anuncia o fim e, no desenrolar da narrativa, o passado e o presente se atravessam conduzidos pelo crivo do discurso fílmico.

No limite, pode-se pensar que o filme evidencia certa tentativa (desesperada por motivos óbvios) de o protagonista voltar às origens para compreender o sentido de determinadas ações, o qual conferirá a previsão de sua ação futura. Suas ações enclausuradas em um presente eterno e dolorido, porque constantemente perdido, registram a perseguição vã do protagonista por recuperar uma memória de um passado sempre fugidio.

Os dilemas enfrentados pelo protagonista de Amnésia tangenciam questões que busquei explorar com este texto. A prática historiográfica, assim como o protagonista de Amnésia, é prisioneira do presente, o discurso que a efetiva como um fazer é sempre invertido em relação a sua lógica procedimental e, apesar das recorrentes tentativas de limpeza e de diferenciação, em seu encarceramento discursivo, a prática (sempre presente) divide espaço com aqueles flashes do passado (ausentes, mortos), que reiteradamente voltam à cela e coabitam o recinto.

O discurso sobre morto, falecido há muito ou há pouco tempo, encontra um túmulo no seu espaço de honraria e retorna à encenação historiográfica, mesmo que sua ausência seja requisitada. 


\section{Referências}

CERTEAU, Michel de. A escrita da história. 2. ed. Rio de Janeiro: Forense Universitária, 2002.

CERTEAU, Michel de. História e psicanálise: entre ciência e ficção. Tradução Guilherme João de Freitas Teixeira. Belo Horizonte: Autêntica, 2011.

CERTEAU, Michel de. Teoria e método no estudo no estudo das práticas cotidianas. In. SZMRECSANYI, Maria Ivone (Org.). Cotidiano, cultura popular e planejamento urbano (Anais do Encontro). São Paulo: FAU/USP, 1985, p. 3-19.

CHARTIER, Roger. Le regard d'um historien modernista. In: INSTITUT D' HISTOIRE DU TEMPS PRÈSENT. Ecrire l'histoire du temps present. Paris: CNRS Editions, 1993.

CHAUVEAU, Agnès; TÉTART, Philippe. Questões para a história do presente. Bauru: EDUSC, 1999.

DOSSE, François. História e ciências sociais. Tradução Fernanda Abreu. Bauru: SP, EDUSC, 2004.

DOSSE, François. História do tempo presente e historiografia. Revista Tempo e Argumento, v. 4, n 1, p. 5-23, jan.-jun., 2012, Disponível em:

<http://revistas.udesc.br/index.php/tempo/article/view/2175180304012012005>. Acesso em: 15 set. 2015 .

FERREIRA, Marieta de Moraes. História, tempo presente e história oral. Topoi, Rio de Janeiro, p. 314-33, dez. 2002,. Disponível em:

<http://www.revistatopoi.org/numeros_anteriores/topoi05/topoi5a13.pdf>. Acesso em: 19 jan. 2016.

FICO, Carlos. História do tempo presente, eventos traumáticos e documentos sensíveis: o caso brasileiro. Varia história, Belo Horizonte, v. 28, n. 47, p. 43-59, jan.-jun. 2012.

Disponível em: < http://www.scielo.br/pdf/vh/v28n47/03.pdf> Acesso em: 27 nov. 2015.

GLEZER, Raquel. A história e o tempo presente. In: BRUNI, José Carlos; BARRETO, Luiz M.; MARQUES, Nelson. (orgs.). Decifrando o tempo presente. São Paulo: Editora Unesp, 2007, p. 23-44.

LE GOFF, Jacques; NORA, Pierre. História: novos problemas. Rio de Janeiro: Francisco Alves, 1976. 
MEIRELES, Cecília. Vitrola. In: MEIRELES, Cecília. Obra poética. Rio de Janeiro: J. Aguilar, Instituto Nacional do Livro, 1958. 1093p.

MULLER, Helena Isabel. História do tempo presente: algumas reflexões. In: PORTO JUNIOR, Gelson. História do tempo presente. Bauru, SP: EDUSC, 2007, p. 17-30.

REVEL, Jacques; CERTEAU, Michel de; JULIA, Dominique. A beleza do morto: o conceito de cultura popular. In: REVEL, Jacques. A Invenção da sociedade. Lisboa: DIFEL, 1989, p. 49-75.

SIRINELLI, Jean-François. Este século tinha sesenta anos: a França dos sixties revisitada. Tempo, v. 8, n. 16, p. 1-21, 2004. Disponível em: <http://www.redalyc.org/html/1670/167017772002/>. Acesso em: 15 nov. 2015.

VEYNE, PAUL. Como se escreve a história. Brasília: Editora Universidade de Brasília, 1998 [1971].

VIDAL, Diana Gonçalves. Michel de Certeau e a difícil arte de fazer história das práticas. In: FARIA FILHO, Luciano Mendes. (Org.). Pensadores sociais e história da educação. Belo Horizonte: Autêntica, 2005, v. 1, p. 257-284.

WHITE, Hayden. Meta-história. A imaginação histórica do século XIX. São Paulo: Edusp, 1995 [1973]. 